For reprint orders, please contact: reprints@futuremedicine.com

\title{
Apoptosis in liver carcinogenesis and chemotherapy
}

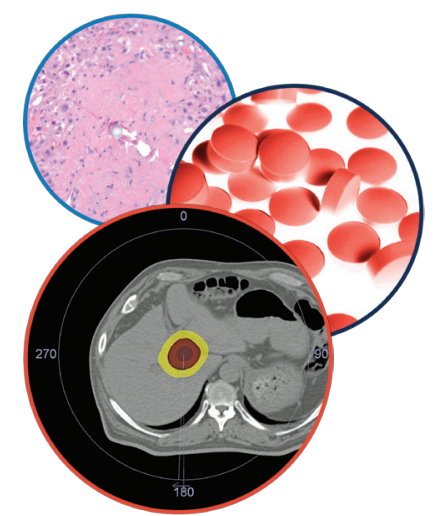

Hepatic Oncology

Joaquim Moreno-Càceres ${ }^{1} \&$ Isabel Fabregatt ${ }^{*, 1,2}$

\section{Practice points}

- Hepatocellular carcinomas (HCC)s show alterations in the Fas pathway molecules, conferring insensitivity to Fas-mediated apoptosis.

- Most HCCs are also insensitive toward TNF-related apoptosis-inducing ligand-mediated cell death.

- TGF- $\beta$ induces apoptosis in hepatocytes. However, TGF- $\beta$ is upregulated in a great percentage of HCC patients.

- TGF- $\beta$ receptors or SMADs expression (and/or function) is not frequently altered in HCC.

- Overactivation of survival signals and epithelial-mesenchymal phenotypic changes cause $\mathrm{HCC}$ cell resistance to TGF- $\beta$-induced cell death.

- Once cells overcome TGF- $\beta$-induced apoptosis, this cytokine acts as a protumorigenic factor.

- Genetic alterations observed in HCC lead to an imbalance in the pro- and anti-apoptotic members of the $\mathrm{Bcl}-2$ family.

- Autocrine activation of intracellular survival signals and/or mutations in genes involved in these processes protect HCC cells from apoptosis.

- Among others, deregulation of the following pathways is relevant in HCC: EGFR, IGF, c-Met, STATs, PI3K/AKT, Ras/MAPK.

- Mutations in the p53 suppressor gene (TP53) are commonly found in HCC and confer resistance to antineoplastic drugs that require p53 to mediate apoptosis.

- Sorafenib is the sole systemic management option demonstrating anti-tumor effects in advanced HCC.

- Sorafenib effectiveness is related to its capacity to induce apoptosis in HCC cells. Indeed, combination with other drugs that amplify HCC cell apoptotic response is a challenge in future therapeutic strategies.

- Histone deacetylase inhibitors sensitize HCC cells to TRAlL-induced apoptosis. Efficacy enhances in combination with sorafenib.

- Combinatorial approaches targeting different survival pathways are a promising target in HCC. A new Met inhibitor synergizes with sorafenib to suppress HCC.

- The use of new technologies that allow the identification of relevant genetic, epigenetic and proteomic alterations in HCC patients will lead to a future of personalized medicine in this disease. 


\section{KEYWORDS}

- apoptosis $\bullet$ death receptors $\bullet \mathrm{HCC} \cdot$ liver

- sorafenib - survival signals

- targeted therapy $\bullet$ TGF- $\beta$
Hepatocellular carcinoma (HCC) is a major health problem. In human hepatocarcinogenesis, the balance between cell death and proliferation is deregulated, tipping the scales for a situation where antiapoptotic signals are overpowering the death-triggering stimuli. HCC cells harbor a wide variety of mutations that alter the regulation of apoptosis and hence the response to chemotherapeutical drugs, making them resistant to the proapoptotic signals. Considering all these modifications found in HCC cells, therapeutic approaches need to be carefully studied in order to specifically target the antiapoptotic signals. This review deals with the recent relevant contributions reporting molecular alterations for HCC that lead to a deregulation of apoptosis, as well as the challenge of death-inducing chemotherapeutics in current HCC treatment.

Apoptosis is a physiological process that allows the maintenance of liver volume and cell number, being relevant during liver development and regeneration [1]. It consists in a chain of molecular events that lead to programmed cell death, with the implication of caspases, a family of cysteine proteases. Apoptosis can be triggered through different pathways, mainly the extrinsic pathway which relies on death receptor-mediated signals or the intrinsic pathway that involves the mitochondria and release of cytochrome c [1]. In both cases, signals converge in the activation of caspase-3, -6, -7, which are the final effectors of apoptosis (Figure 1). A lack of apoptosis has been associated with development and progression of tumors of the liver and the biliary tree $[1,2]$. In addition, the deregulation of the ratio proliferation/apoptosis has also been found in preneoplastic cells, where cell proliferation is higher than apoptosis, giving a hint of its important role in hepatocarcinogenesis $[3,4]$. These features may be useful in the detection and treatment of precancerous lesions $[4,5]$.

Hepatocellular carcinoma (HCC) is a major health problem, being the second cause of cancer-related deaths globally [6]. It is a heterogeneous tumor commonly associated with chronic liver diseases, which frequently culminate in cirrhosis, such as alcoholic cirrhosis and chronic HBV and HCV infections. During recent years, major advancements have been made in order to better understand the mechanisms of the disease and the identification of novel therapeutic targets. Sorafenib has been established as the main drug of choice in HCC [7] and, accordingly, the knowledge about the mechanisms that permit HCC cells to either escape or succumb to the treatment are being studied.

This article will start by defining the main pathways responsible for apoptosis regulation in liver cells and how some of them are altered in HCC, given their importance as potential therapeutic targets. Next, it will highlight the relevance of apoptosis in the efficiency of chemo- and targeted-therapeutic drugs in this disease.

The death receptor pathways

Death receptors are cellular membrane receptors that trigger the extrinsic apoptosis pathway when bound to its specific ligands; these are CD95 receptor (Apo1/Fas receptor); TNF receptor type 1 ( $\mathrm{p} 55 / 65, \mathrm{CD} 120 \mathrm{a})$ and type 2 (p75/80, CD120b); and TRAIL receptor type 1 and type 2 (Figure 1) [8].

The majority of the HCCs show alterations in Fas pathway molecules, such as soluble Fas and FAP-1, which confer insensitivity to Fas-mediated apoptosis [9]. Fas targeting by HBV-upregulated miRNAs has also been described [10]. The status of Fas and Fas ligand expression can predict HCC recurrence [11]. Loss of response to Fas in HCC cells may be produced either by downregulation of Fas expression [9,12], concomitant with decreased expression of downstream molecules, such as FADD or FLICE/Caspase-8 [12] or by upregulation or overactivation of molecules that counteract its proapoptotic effect, including NF- $\mathrm{BB}, \mathrm{Bcl}-2$ or $\mathrm{Bcl}-\mathrm{X}_{\mathrm{L}}[13-15]$. Recent investigations have evidenced cellular targets that could sensitize cells to Fas-mediated apoptosis in HCC. Indeed, Fas mRNA has been found to interact with $\mathrm{HuR}$, which blocks mRNA translation and is overexpressed in human HCC tumor tissues compared with normal liver tissues [16]. Moreover, ORP8, which is downregulated in HCC tissues compared with liver tissue from healthy subjects, has a role in Fas translocation to the plasma membrane and Fas ligand upregulation in liver tumor cells [17]. cFLIP, an intracellular inhibitor of caspase- 8 activation, is constitutively expressed in human HCC cell lines and displays higher levels in HCC tissues than in nontumoral liver tissues [18]. Overexpression of BRE, which has been described in HCC 


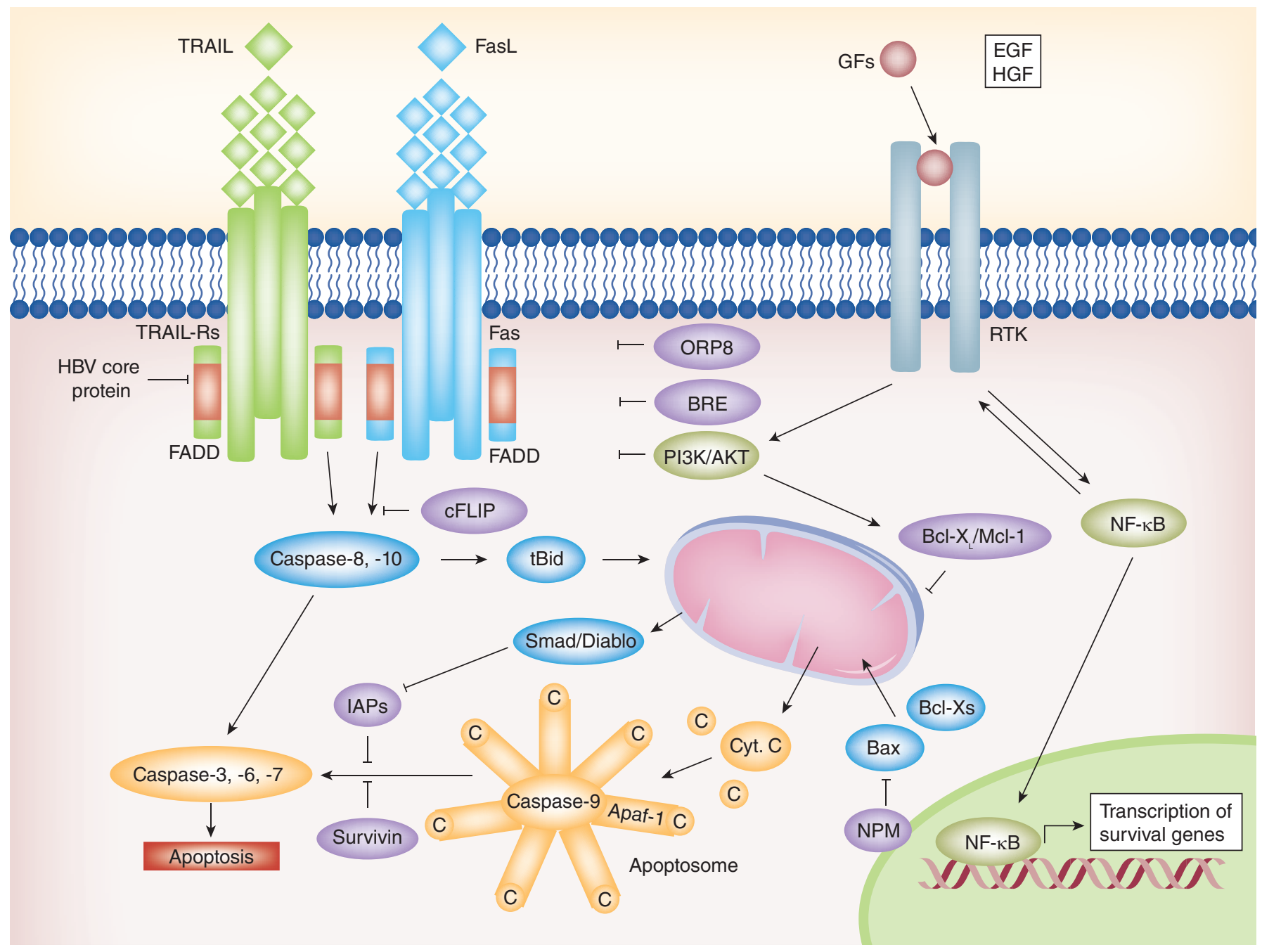

Figure 1. Alterations in the expression or functions of death receptor pathways and apoptosis regulatory proteins in hepatocellular carcinoma cells. Different molecules act as activators or inhibitors of these pathways as the Bcl-2 family of proteins, which contains proapoptotic members such as BAX and $\mathrm{Bcl}-\mathrm{X}_{\mathrm{s}^{\prime}}$ and antiapoptotic members such as $\mathrm{Bcl}-\mathrm{X}_{\mathrm{L}}$ and $\mathrm{Mcl}-1$. See text for further details. FADD: Fas-associated protein with death domain; TRAIL: TNF-related apoptosis-inducing ligand.

tissues, is an antiapoptotic protein that binds to the cytoplasmic domains of TNF-R1 and Fas, attenuating death-receptor-initiated apoptosis [19] and promoting HCC growth [20]. Moreover, it has been suggested that extracellular factors might counteract Fas-induced apoptosis in HCC cells. Indeed, HGF, through activation of the PI3K/AKT pathway, suppresses Fas-mediated cell death in human HCC cell lines, by inhibiting DISC formation [21] and inducing Bcl- $\mathrm{X}_{\mathrm{L}}$ [22].

TRAIL selectively induces apoptosis in various transformed cell lines but not in normal tissues [23]. Certain evidence indicates that most HCC cells are insensitive toward TRAILmediated apoptosis, suggesting that the presence of mediators can inhibit the TRAIL cell death-inducing pathway in HCC $[24,25]$. It has been reported that HBV core protein inhibits TRAIL-induced apoptosis by blocking the expression of the TRAIL receptor 2 [26]. Overactivation of $\mathrm{NF}-\kappa \mathrm{B}$ and $\mathrm{Bcl}-\mathrm{X}_{\mathrm{L}}$ in $\mathrm{HCC}$ cells restrains the TRAIL-mediated apoptosis [27]. Further studies trying to determine the causes of TRAIL-induced apoptosis resistance have identified ISG12a, which regulates sensitivity to TRAIL, to be decreased in TRAILresistant cancer cells. It has also been described that the miRNA miR-942 is controlling ISG12a expression, hence offering a novel drug response marker in HCC therapy [28].

In summary, liver tumors harbor different mutations that lead to death receptor-induced 
cell death resistance. Sensitization to these death-inducing pathways may be a therapeutic approach to trigger apoptosis in HCC.

\section{The TGF- $\beta$ pathway}

The TGF- $\beta$ family of cytokines plays a physiological role during embryonic development and its misregulation can result in tumorigenesis [29]. TGF- $\beta 1$ is an important suppressor factor in nontransformed hepatocytes, inhibiting proliferation [30] and inducing cell death [31,32]. However, TGF- $\beta$ also has a protumorigenic role, modulating processes such as cell migration and invasion, immune regulation or microenvironment modification [29,33]. Furthermore, TGF- $\beta 1$ mediates liver fibrogenesis [34], which leads to cirrhosis, a condition that frequently develops HCC.

TGF- $\beta$ plays a dual role in the control of proliferation and apoptosis in immature hepatocytes and liver tumor cells (Figure 2). On the one hand, early on, TGF- $\beta$ induces intracellular signals that mediate cell cycle arrest and apoptosis, but on the other hand, at later times, it activates proliferative and antiapoptotic signals [35-37], through activation of the EGFR pathway [38-41]. EGF is an important survival signal counteracting TGF- $\beta$-induced apoptosis in hepatocytes [42], a process that requires activation of the PI3K/AKT axis to counteract TGF- $\beta$-induced upregulation of NOX4, oxidative stress and mitochondrial-dependent apoptosis $[43,44]$. The autocrine loop of EGFR activated by TGF- $\beta$ in liver cells would require the activity of the metalloprotease responsible for the shedding of TNF- $\alpha$ : TACE/ADAM17 [38,39], which is also responsible for the shedding of the EGF family of growth factors (Figure 2) [45].

Hepatocytes that escape from TGF- $\beta$-induced apoptosis undergo epithelial to mesenchymal transition (EMT), which is involved both in physiological processes such as embryonic development and in pathological ones such as neoplasia and fibrosis [46]. It concurs with lose of E-cadherin and other epithelial cell markers expression and the acquisition of mesenchymal cell properties, such as reorganization of the cytoskeleton, altogether contributing to increased motility and invasiveness [46]. Liver cells that undergo EMT are resistant to TGF- $\beta$-mediated apoptosis $[47,48]$, due to upregulation of $S N A I-1$, the gene that codifies for Snail, a repressor of E-cadherin expression [49]. Fetal hepatocytes and hepatoma cells that have undergone a TGF- $\beta$-mediated EMT express high levels of TGF- $\alpha$ and HB-EGF, which confer survival through the activation of the EGFR pathway [39,50].

A classification of liver tumors has been established according to the TGF- $\beta$-responsive genes they express; HCCs with a late TGF- $\beta$-signature (antiapoptotic and metastatic genes) display a higher invasive phenotype and increased tumor recurrence when compared with the tumors that show an early TGF- $\beta$-signature (suppressor genes) [51]. Therefore, escaping from the antiproliferative and proapoptotic role of TGF- $\beta$ may be a prerequisite for hepatocarcinoma progression [52]. The Smad-dependent suppressor arm could be altered in some HCC cells. TGF- $\beta$ dependent cytostasis is blunted in a group of HCC cell lines expressing high amounts of TGF- $\beta$ and Smad7 and showing significantly reduced Smad3 signaling [53]. In this line of evidence, overexpression of Smad3 has been shown to reduce the susceptibility to develop HCC, as it sensitizes hepatocytes to apoptosis through downregulation of $\mathrm{Bcl}-2$ [52]. Viral infections, such as HBV, can abrogate TGF- $\beta$ signaling via upregulation of Smad7, hence inhibiting TGF- $\beta$-induced apoptosis [54]. It has been also proposed that HCC onset would depend on the loss of ELF, an important Smad3/4 adaptor [55,56]. In addition, reduced TGF- $\beta$ receptor-2 (TGFBR2) expression has been associated with more aggressive features of HCC [57] . Nevertheless, alterations at TGF- $\beta$ receptors or Smads levels are not as frequent in HCC as they appear to be in colon or pancreatic cancer [58]; moreover, expression of TGF- $\beta$ is upregulated in a great percentage of HCC patients [51,59]. Hence, other ways to disrupt TGF- $\beta$ signaling may exist, probably altering just downstream signals in the tumor-suppressive branch, which would promote, or facilitate, the tumorigenic arm.

HCC cells overexpress a specific set of miRNAs that would allow the escape from TGF- $\beta$-induced apoptosis [60-62]. As an example, miR-183, which has been shown to be upregulated in HCC samples, can inhibit apoptosis by repressing the expression of the proapoptotic molecule involved in TGF- $\beta 1$-induced apoptosis, PDCD4, in human HCC cells [62]. Most importantly, overactivation of survival signals in HCC cells may be also associated with the impairment of the TGF- $\beta$ suppressor arm observed in these tumor cells. Further details on that specific topic will be mentioned below but, 


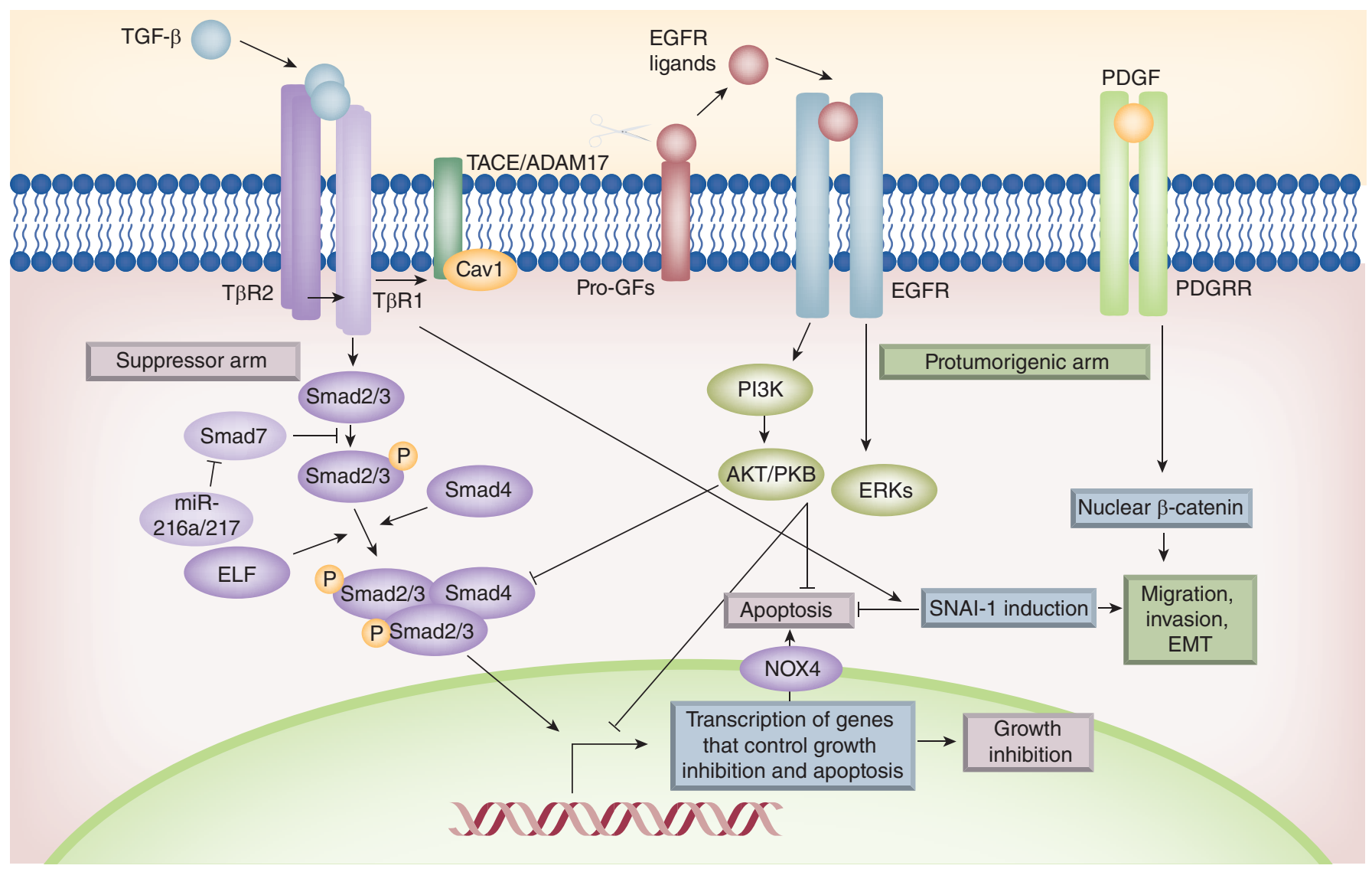

Figure 2. Deregulation of the TGF- $\beta$ pathways in hepatocellular carcinoma cells favors its protumorigenic activities. The autocrine loop of EGFR activated by TGF- $\beta$ in liver cells requires the activity of the metalloprotease TACE/ADAM17, which is responsible for the shedding of the EGF family of growth factors. In addition to the EGFR pathway, crosstalk between TGF- $\beta$ and other growth factors and chemokine pathways has been established. See text for further details.

in particular, it is worthy to mention here, that during hepatocarcinogenesis an increase in the activity of the metalloprotease TACE/ADAM17 may promote the antiapoptotic arm of the TGF- $\beta$ signaling [39]. Whereas in fetal hepatocytes and hepatoma cells, TGF- $\beta$ induces both EGFR ligands (TGF- $\alpha$ and HB-EGF) expression and TACE/ADAM17 activity, in adult hepatocytes the induction in TGF- $\alpha$ and HB-EGF has no impact on cell survival because these cells express very low levels of TACE/ADAM17 [39]. Recent results have proved that the structural protein Caveolin-1 is required for the proper function of TACE/ADAM17 in hepatocytes, thus Caveolin-1 could be another important regulator of the TGF- $\beta$ signaling [63]. Supporting this hypothesis, it has been evidenced that Caveolin-1 expression is increased in late TGF- $\beta$-signature HCC cells, as well as in advanced stages of hepatocarcinogenesis $[64,65]$. Furthermore, the crosstalk between EMT and apoptosis would explain the resistance to TGF- $\beta$-induced suppressor effects observed in HCC cells. Indeed, the autocrine stimulation of TGF- $\beta$ in human liver tumor cells has been shown to correlate with a mesenchymal-like phenotype and resistance to TGF- $\beta$-induced suppressor effects [66]. Blocking TGF- $\beta$ upregulates E-cadherin and reduces migration and invasion of HCC cell lines [66,67].

Additionally to the EGFR pathway, crosstalk between the TGF- $\beta$ and other growth factors and chemokine pathways has been found, which may contribute to its protumorigenic actions in liver tumorigenesis. TGF- $\beta$ activates the $\beta$-catenin pathway, through induction of the PDGF signaling [68], which mediates EMT, migration and survival in HCC cells (Figure 2). Indeed, Mikulits and colleagues have described the importance of the TGF- $\beta / P D G F$ axis during hepatic tumor-stroma crosstalk, being crucial in the regulation of both tumor growth and cancer progression [69]. Interestingly, a 
crosstalk between TGF- $\beta$ and chemokine signaling has been recently reported. Indeed, TGF- $\beta$ induces the expression of the chemokine receptor CXCR4 in HCC cells, which is required for TGF- $\beta$-induced cell migration and cell survival [66]. TGF- $\beta$ also regulates the CTGF expression in HCC invasive cells, which is responsible for the tumor/stroma crosstalk [70].

In conclusion, a great percentage of HCC cells show alterations in the response to TGF- $\beta$ in terms of apoptosis, which allows it to act as a protumorigenic factor.

Alterations in the expression or function of apoptosis regulatory proteins

Many of the genetic alterations observed in HCC lead to an imbalance in the pro- and anti-apoptotic members of the Bcl-2 family (Figure 1) [71]. $\mathrm{Bcl}-\mathrm{X}_{\mathrm{L}}$ is overexpressed in a great percentage of human HCC tissues [72], and so is Mcl-1 [73]. In contrast, proapoptotic members of the family, such as BAX or Bcl-X $\mathrm{S}_{\mathrm{s}}$, are downregulated in HCC tumor tissues with dysfunction in the p53 pathway [74]. Moreover, some proapoptotic members of the $\mathrm{BH}-3$-only family, such as BID, show decreased expression in HCC related to HBV or HCV infection [75].

It has been revealed that a high percentage of clinical tumors from advanced HCC patients express high levels of XIAP, an inhibitor of caspases. Studies in established HCC cell lines indicated a correlation of metastasis with resistance to apoptosis and increased expression of XIAP [76]. XIAP might also function as a cofactor in TGF- $\beta$ signaling [77], thus, overexpression of XIAP might confer resistance to the apoptotic effects of TGF- $\beta$, allowing HCC cells to respond to this cytokine in terms of migration and invasion. Alterations in IAP family proteins, including Survivin and Livin/ML-IAP, are frequent in HCC. It has been demonstrated that they are significantly overexpressed in HCC tissues [78]. In addition, a significant relation has been found between higher Survivin mRNA level and tumor stage, tumor grade and vascular invasion [79].

Recent investigations have identified NPM as a key factor that counteracts death stimuli in human HCC cells. NPM is bound to BAX and in response to cell stress, it translocates from the nucleolus to cytosol where it binds to BAX, and blocks mitochondrial translocation, oligomerization and activation of BAX, triggering resistance to death induction. Silencing NPM sensitizes HCC cells, especially those with inactivated $\mathrm{p} 53$, to chemotherapy and targeted therapies, a fact that points out NPM/BAX axis as possible new target [80]. Additionally, Bcl-2 expression in HCCs has also been associated with miR-34a, a direct target of $\mathrm{p} 53$, which is downregulated in some HCC tissues. Restoration of miR-34a expression promotes cell apoptosis and potentiates sorafenib-induced apoptosis in HCC cells by inhibiting Bcl-2 expression [81].

Concluding, HCC cells show an imbalance in the expression of pro- and anti-apoptotic proteins, which favors cell survival and provides a tool for new therapeutic approaches.

Overactivation of survival signals

Autocrine activation of intracellular survival signals in liver tumor cells protects them from apoptosis induced by stress, physiological factors or drugs that trigger apoptosis (Figure 3) [82,83]. Deregulation of growth factor signaling, including EGF and IGF-1 pathways, has been well established in human HCCs [84,85]. An increased expression of EGFR ligands in tumors suggests a relevant role in HCC [83]. Overactivation of the EGFR pathway in liver tumor cells induces basal growth (in the absence of serum) and protection from proapoptotic agents, such as doxorubicin, generating drug resistance [86]. Interestingly, blockade of EGFR or c-Src in primary untransformed hepatocytes only marginally increases cell death $[86,87]$, which indicates that both tyrosine kinases are critical effectors that specifically protect liver tumor cells from death-triggering stimuli, providing a target for a potential therapeutic approach. Another tyrosine-kinase receptor which has been related to hepatocarcinogensis is c-Met, whose direct ligand is the HGF [88] . c-Met signaling has a role in different cellular processes such as mitogenesis, motogenesis or morphogenesis depending on cell type [88]. The alteration of c-Met might result in aberrant growth and differentiation, hence promoting malignant transformation [89]. In HCC, c-Met has been found to be overexpressed both at mRNA and protein levels when compared with nontumoral tissues [88]. Furthermore, HBX is an inducible factor for c-Met expression in the HCC cell line HepG2 [90]. The use of a selective c-Met tyrosine kinase inhibitor (PHA665752) inhibited cell proliferation and induced apoptosis in c-Met-positive HCC cell lines [91]. In terms of c-Met activation in HCC, it has been described a crosstalk between c-Met and EGFR [92]. A reciprocal activating crosstalk between c-Met and Caveolin-1 has also 
been associated with initiation and progression of HCC, according to HCC tissue samples [93].

STAT proteins are activated by tyrosine kinases in response to cytokines and growth factors (Figure 3). SOCS-1 and SOCS-3, negative regulators of the JAK2-STAT signaling pathway, are silenced by methylation in human hepatoma cell lines and HCC tissues, which leads to constitutive activation of STAT3 in these cells [94,95]. Deletion of SOCS-3 in hepatocytes promotes activation of STAT3, resistance to apoptosis and increased proliferation, resulting in enhanced hepatitis-induced hepatocarcinogenesis [96]. Differential antiproliferative effects of STAT3 inhibition have been observed in HBV-related HCC cells, which are more resistant than nonHBV-related ones, caused by an enhanced ERK activation after STAT3 blockade [97]. Abrogation of constitutive JAK/STAT3 pathway through restoration of SOCS-3 by an oncolytic adenovirus can antagonize therapeutic resistance to TRAIL and induce cell cycle arrest in HCC cell lines through downregulation of cyclin D1 and antiapoptotic proteins such as XIAP, Survivin, Bcl- $\mathrm{X}_{\mathrm{L}}$ and Mcl-1 [98]. Regarding SOCS-1 and SOCS-3 regulation, they have been identified as targets of the miR-221, which is upregulated and plays a role in tumorigenesis of $\mathrm{HCV}$-associated HCC [99].

The PI3K/AKT pathway is also altered in HCC. The expression of PTEN gene is reduced or absent in almost half of HCCs and hepatocyte-specific abrogation of PTEN expression in mice results in the development of HCC [100]. Interestingly, overexpression of PTEN in liver tumor cells sensitizes them to sorafenib treatment in terms of its ability to inhibit proliferation and to induce apoptosis [101]. PTEN overexpression decreases MEK phosphorylation, levels of cyclin D1, Bcl-2 and VEGF [101]. The expression of a negative regulator of PI3K (PIK3IP1) is reduced in most cases of human HCC, pointing to a tumor suppressor-like function of this protein [102]. New therapeutic targets in the $\mathrm{PI} 3 \mathrm{~K} / \mathrm{AKT} / \mathrm{mTOR}$ pathway are being discovered using targeted next-generation sequencing, which will lead to a better design of targeted therapies [103]. Regarding miRNA regulation in HCC, recent studies have demonstrated that the miR-3127 suppresses multiple phosphatases, such as PHLPP 1/2, INPP4A and INPP5J (responsible of PI3K/AKT deactivation in physiological conditions), hence promoting growth of HCC. MiR-3127 expression is markedly upregulated in HCC tissues and cells and is associated with an aggressive phenotype and poor prognosis [104]. Taken together, all these findings define the PI3K/AKT axis as a targetable survival pathway.

The Ras/MAPK pathway is a fundamental regulator of major cellular processes, such as cellular survival and proliferation (Figure 3). Its alterations have been found in malignant transformation processes such as liver cancer [105]. Overactivation of Ras proteins [106] and increased expression and activation of the MAPKs MEK1/2 and ERK1/2 are frequently observed in HCC [107]. In fact, the overactivation of the MEK/ERK pathway in liver tumor cells is responsible for their refractory status to the proapoptotic effects of TGF- $\beta$, and its inhibition sensitizes them to cell death through a mitochondrial-dependent mechanism, coincident with increased levels of BIM and BMF, decreased levels of Bcl- $\mathrm{X}_{\mathrm{L}}$ and Mcl-1 and BAX/BAK activation [108]. Furthermore, upregulation of the Ras pathway is mainly associated with disruption of upstream signals or downregulation of Ras/MAPK inhibitors in human HCCs [107]. For instance, Ras GAPs inactivation has been described in several human HCC cell lines [109]. The Ras inhibitors RASSF1A and NORE1A regulate Ras function by inducing caspaserelated and caspase-independent cell apoptosis once bound to Ras [107], therefore their deregulation may lead to carcinogenesis. Some evidence suggests that RASSF1A inactivation, mainly due to promoter methylation, is a necessary event in HCC [110-112]. SPRED, a physiological negative regulator of the Ras/Raf-1/ERK pathway, might function as a tumor suppressor in human HCC, as low SPRED expression levels correlate with more aggressive hepatocellular tumors [113]. Another ERK regulator, DUSP1, has also been found deregulated in HCC tissues [114]. Finally, targeting the Ras/MAPK pathway may also be considered as a therapeutical approach [107].

In summary, several molecular alterations lead to an enhancement of antiapoptotic signals in HCC cells, which allow them to survive to proapoptotic stimuli.

\section{The $\mathrm{p} 53$ pathway}

One of the most common alterations found in HCC is mutations in the suppressor gene TP53 [115]. In response to different types of cellular stress, p53 is stabilized and turned into an active transcription factor that regulates the expression of specific target genes that mediate cell cycle, senescence, DNA repair and apoptosis [116]. An important point of regulation of $\mathrm{p} 53$ is through its 


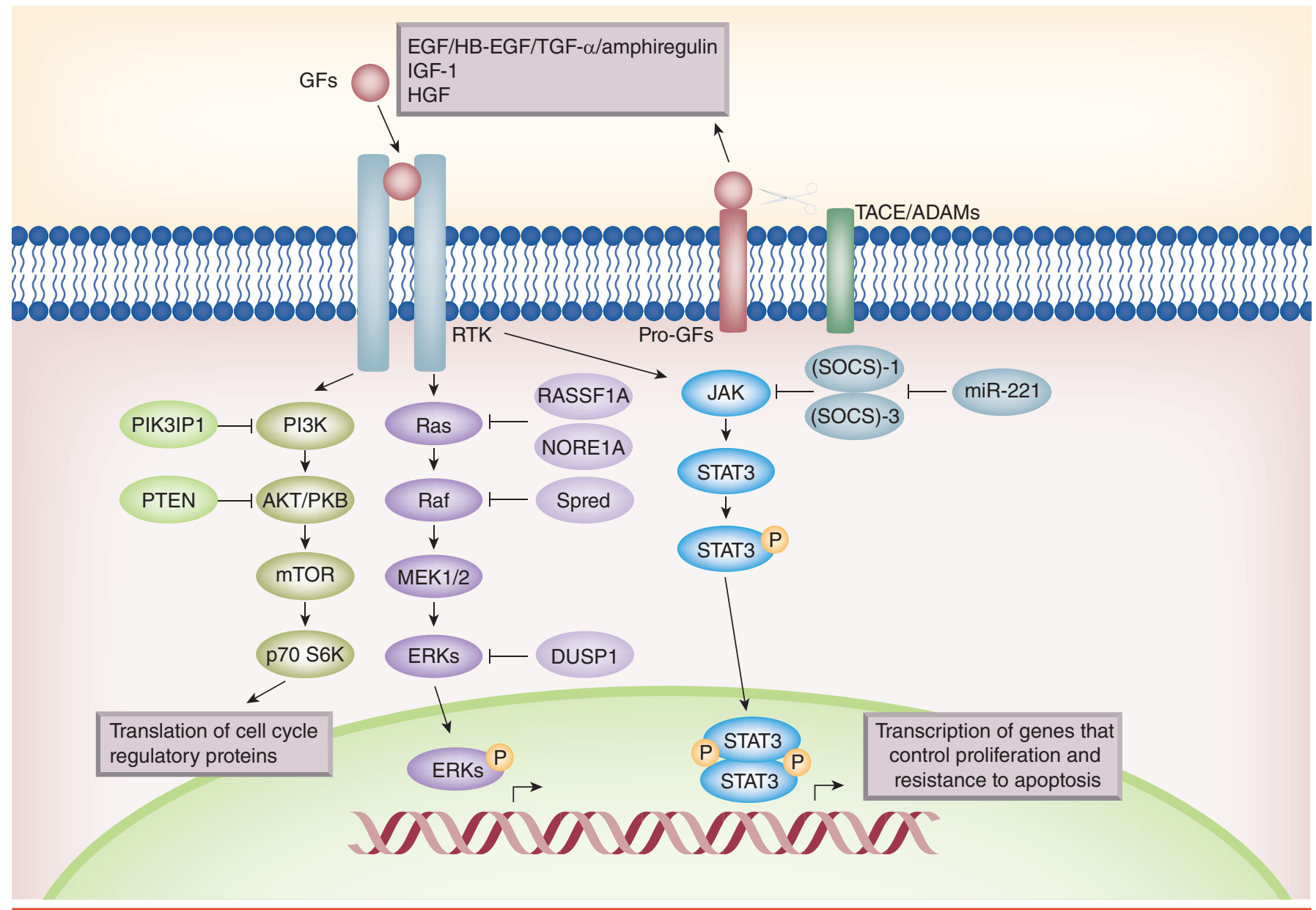

Figure 3. Overactivation of survival signals in hepatocellular carcinoma cells. Growth factors bind to tyrosine kinase receptors triggering different signaling pathways that mediate survival. Among them, it is important to remark the PI3K/AKT axis, the Ras/ERKs and the JAK/STAT pathways. All of them are regulated by inhibitory proteins (marked in lighter color in the figure). See text for further details.

with $\mathrm{HBV}$ and $\mathrm{HCV}$ viruses, and exposure to oxidative stress induce DNA damage and mutations in cancer-related genes such as TP53. A recent exome sequencing analysis of 243 liver tumors has identified TP53 alterations to appear at more advanced stages in aggressive tumors [118]. In the same study, mutations of TERT promoter were identified as an early event in HCC progression [118]. These findings correlate with previous results that hypothesized that a decreased $\mathrm{p} 53$ function could contribute to hepatocyte survival in the presence of telomere-induced chromosomal instability [119].

Relevance of the apoptotic pathways in the effectiveness of chemo-

\& targeted-therapeutic drugs in HCC

$\mathrm{HCC}$ can be treated with surgical resection or liver transplantation when diagnosed at exposure to aflatoxin B1, in association with $\mathrm{HBV}$ infection [115]. Moreover, both chronic infection 
early stages; however, the majority of patients are diagnosed at advanced stages, leading to a poor prognosis. The lack of efficient treatment options at late stages is a severe problem, and despite the many efforts, a completely efficient therapy is yet to be discovered.

\section{- Role of apoptosis during sorafenib treatment}

Chemotherapy is not routinely used due to its low response versus adverse effects ratio. Monotherapy as well as several combinational regimens have been tested, but none of them has proved its efficacy in prolonging patient survival [7]. This fact has moved research to a more targeted perspective, evaluating new approaches that take advantage of the knowledge on molecular targets in HCC. The first molecular-targeted drug to be approved was sorafenib, a multikinase inhibitor targeting the Raf serine/threonine kinases and the VEGF receptors 1-3, PDGF receptor-b, c-Kit, FLT-3 and p38 tyrosine kinases [120]. Despite its proved effectiveness, many targets of sorafenib are still being studied, as well as the mechanisms that trigger resistance to this drug in HCC patients (for whom no standard treatment exists). Sorafenib has been described as apoptosisinducer in HCC cells, through upregulation of the proapoptotic PUMA and BIM, downregulation of the antiapoptotic Mcl-1 and Survivin, activation of BAX and BAK, release of cy tochrome $\mathrm{c}$ and increase in caspase-3 activity (Figure 4) [121]. Furthermore, this same study demonstrated that sorafenib sensitizes HCC cells to the effects of physiological proapoptotic factors, such as TNF- $\alpha$ or TGF- $\beta$ [121]. The relevance of the apoptosis in the therapeutic effectiveness of sorafenib comes from a recent study that evidences that liver tumor cells that respond in vitro to sorafenib-inducing growth arrest but not cell death induce in vivo tumors in nude mice xenografts that are resistant to sorafenib treatment [122]. These unresponsive HCC cells to sorafenib show a mesenchymal-like phenotype, late TGF- $\beta$ signature and high expression of the stem cell marker CD44. Interestingly, CD44 knockdown in these mesenchymal-like HCC cells promotes sensitization to sorafenibinduced apoptosis, indicating that CD44 expression might be useful as a prognostic marker in sorafenib treatment, as well as a candidate for future-targeted therapies in combination with sorafenib (Figure 4) [122]. In pursue of a better understanding of the mechanisms that cause tumor resistance, Liu et al. have studied the function of the oncomiR miR-222, which confers sorafenib resistance. Results have shown that miR-222 regulates PI3K/AKT signaling pathway, hence promoting cell proliferation, migration, invasion and decreasing cell apoptosis, which could enhance sorafenib resistance [123]. PTMA, which is overexpressed in human HCC and positively regulated by the oncoprotein c-Myc, has also been described as a protective factor against sorafenib-induced cell death in HCC cells [124]. Notch3 inhibition increases the apoptotic effect of sorafenib in HCC cells through the specific downregulation of $\mathrm{p} 21$ and upregulation of pGSK3 $\beta$ Ser9 [125]. Recent results have shown that sorafenib upregulates HIF- $2 \alpha$, which contributes to hypoxic HCC cells resistance by activating the TGF- $\alpha$ / EGFR pathway [126]. As a matter of fact, the same study proves that the blocking of the TGF- $\alpha /$ EGFR pathway, using the specific EGFR inhibitor gefitinib, synergizes with sorafenib to inhibit proliferation and induce apoptosis of hypoxic HCC cells [126]. Another example of the relevance of apoptosis in the effectiveness of sorafenib in HCC cells is a recent study demonstrating that IFN- $\alpha$ and sorafenib synergistically suppress HCC cell viability, arrest cell cycle and induce apoptosis by regulating cell cycle-related proteins as well as the prosurvival $\mathrm{Bcl}-2$ family proteins Mcl-1, Bcl-2 and Bcl- ${ }_{\mathrm{L}}$ [127]. Retinoic acid in combination with sorafenib could also enhance HCC cells apoptosis through the activation of AMPK (Figure 4) [128].

\section{- Inducing cell death pathways as a therapeutic approach}

Further therapeutical approaches deal with the increase of cell death receptor pathways, hence improving tumor cell sensitivity to death receptor-ligands or establishing new synergistic effects in combination with other drugs. Different therapeutic strategies are focused on TRAIL-induced cell death sensitization of HCC. Of clinical relevance, proteasome and HDAC inhibitors sensitize HCC cells, but not primary human hepatocytes, to TRAILinduced apoptosis $[129,130]$. It has also been proposed that TRAIL enhances the efficacy-inducing apoptosis in HCC cells of a combinatorial treatment consisting of sorafenib and HDAC inhibitors [131]. Recent results have proved that an AKT/NF- $\mathrm{KB}$ signaling inhibitor (OSU-A9) 
synergizes with Apo2L/TRAIL in mediating apoptotic death in HCC cells [132].

Another therapeutic strategy that has been considered is targeting apoptosis-regulatory proteins aiming for the increase of proapoptotic pathways. Interestingly, a recent multicenter, randomized, open-label, Phase II trial using the XIAP antisense AEG35156 in combination with sorafenib showed additional activity in terms of objective response rates (Table 1) [133]. Furthermore, different studies have shown a therapeutic activity of survivin silencing, either alone or in combination with sorafenib and chemotherapy in cell lines [134-136]. The antiapoptotic protein $\mathrm{Bcl}-2 / \mathrm{X}_{\mathrm{L}}$ has also been established as a possible therapeutic target. However, its inhibition using ABT-263 has shown resistance through an increase in Mcl-1 mRNA and protein stability [137]. Another inhibitor of Bcl-2, ABT-737, has also shown resistance in HCC cells expressing high levels of $\mathrm{Bcl}-2$ via activation of the ROS-JNK-autophagy pathway [138].

\section{- Therapies targeting overactivated} survival pathways in HCC

Due to the frequent overactivation of the EGFR in HCC, anti-EGFR antibodies or specific inhibitors are being tested for HCC treatment. Erlotinib, an inhibitor of EGFR/HER1, induces growth inhibition in HCC cells, which correlates with overexpression of proapoptotic factors like caspase and gads [139]. However, the SEARCH trial that combined sorafenib with erlotinib for HCC patients did not show

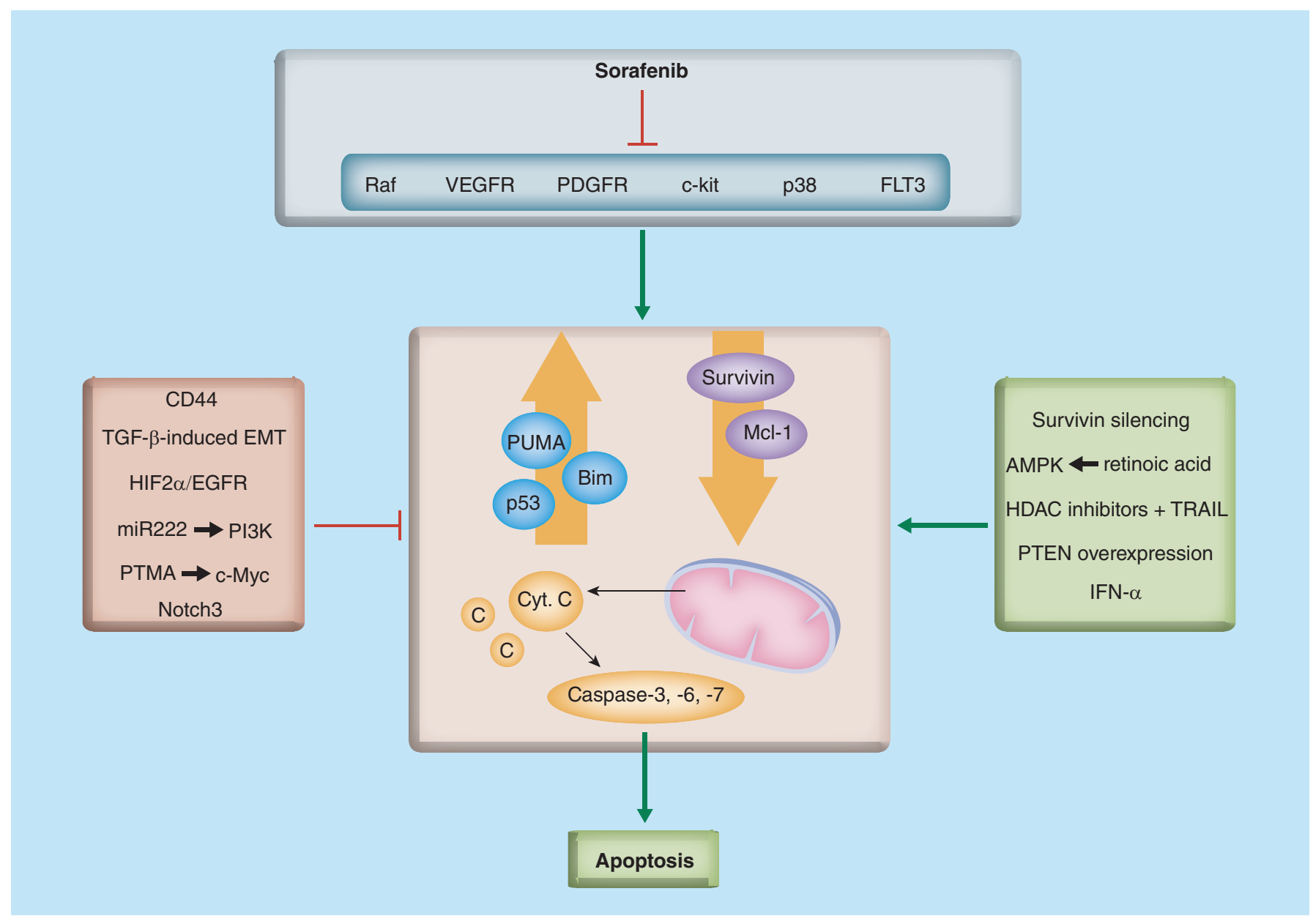

Figure 4. Different pathways converge in promotion or inhibition of sorafenib-induced apoptosis in hepatocellular carcinoma. Sorafenib has been described as apoptosis-inducer in HCC cells, through upregulation of the proapoptotic PUMA and BIM, downregulation of the antiapoptotic Mcl-1 and Survivin, activation of BAX and BAK, release of cytochrome c and increase in caspase-3 activity. Different pathways and molecules have been shown to regulate sorafenib effects in hepatocytes, having either an inhibitor or an activator role. See text for further details. 
positive results (Table 1) [140]. IGF signaling is another target that has been studied, given that a percentage of early HCCs show alterations in the IGF axis, such as upregulation of IGF-2 [141]. Unfortunately, all trials using antiIGF monoclonal antibodies up to date have not resulted in a successful outcome (Table 1) [7]. Considering the discouraging results of many of the clinical trials performed, it is clear that a better understanding of the liver tumor is needed. HCCs are very heterogeneous tumors and thus a biomarker-enriched selection of patients could improve the activity of certain agents that otherwise fail in unselected populations. The use of new technologies that allow the identification of relevant genetic, epigenetic and proteomic alterations will lead to a future of personalized medicine in advanced HCC [142]. Comprehensive study of liver tumors has led to the use of the c-Met tyrosine kinase inhibitor tivantinib (ARQ197). Tivantinib is a selective c-Met receptor inhibitor that inhibits the proliferation of c-Met-expressing cancer cells and induces caspase-dependent apoptosis in cell lines with constitutive c-Met activity [143]. c-Met expression in HCC correlates with late recurrence after tumor resection but it is not a predictor of survival [144]. However, in patients with high c-Met expression, the treatment with tivantinib caused an increase in overall survival when compared with placebo (Table 1) [145]. Further studies have shown that a new Met inhibitor (DE605) synergizes with sorafenib to suppress growth of HCC tumor xenografts in athymic nude mice [146]. All these evidences open a new field of study and the possibility of a second treatment option in patients with sorafenib resistance.

Finally, survival pathways such as the Ras/ERKs have also been considered as a druggable target. For instance, a Phase II clinical trial evaluating the combinatorial treatment of the MEK1/2 inhibitor refametinib (BAY86-9766) and sorafenib in HCC patients has shown that patients with $R A S$ mutations appear to benefit from this combinatorial approach (Table 1) [147].

\section{- p53 as a therapeutic approach}

Given the importance of $\mathrm{p} 53$ as a regulator of cell death, the reactivation of its function has been considered as a therapeutic approach. The adenoviral delivery of $\mathrm{p} 53$ recombinant DNA into HCC bearing mice did not show any promising results [148]. However, the use of a trans-splicing strategy that repaired mutant p53 transcripts in HCC cells resulted in cell cycle arrest, apoptosis and blockage of tumor

\section{Table 1. Clinical trials in hepatocellular carcinoma addressing cell death through different mechanisms.}

\begin{tabular}{|c|c|c|c|c|}
\hline Clinical trial & Type & Phase & Identifier & Ref. \\
\hline Mapatumumab (HGS1012) + sorafenib vs sorafenib & Monoclonal antibody against TRAIL-R1 & II & NCT01258608 & \\
\hline Resminostat (4SC-201) + sorafenib vs sorafenib & HDAC inhibitor & II & NCT00943449 & \\
\hline XIAP antisense (AEG35156) + sorafenib vs sorafenib & XIAP antisense & I-II & NCT00882869 & {$[133]$} \\
\hline Cixutumumab (IMC-A12) + sorafenib vs sorafenib & Monoclonal antibody against IGF-1R & II & NCT00906373 & {$[7]$} \\
\hline AZD6244 + sorafenib vs sorafenib & MEK1/2 inhibitor & $I-I I$ & NCT01029418 & \\
\hline Refametinib (BAY86-9766) + sorafenib vs sorafenib & MEK1/2 inhibitor & II & NCT01915602 & \\
\hline Refametinib (BAY86-9766) + sorafenib vs sorafenib & MEK1/2 inhibitor & II & NCT01204177 & {$[147]$} \\
\hline Erlotinib + sorafenib vs sorafenib & EGFR/HER1 inhibitor & III & NCT00901901 & {$[140]$} \\
\hline MSC2156119J & c-Met inhibitor & $I-I I$ & NCT02115373 & \\
\hline Golvatinib (E7050) + sorafenib vs sorafenib & c-Met and VEGFR2 inhibitor & I-II & NCT01271504 & \\
\hline Everolimus (RAD001) + sorafenib vs sorafenib & mTOR inhibitor & 1 & NCT00828594 & \\
\hline \multicolumn{5}{|l|}{ Addressing the TGF- $\beta$ pathway } \\
\hline LY2157299 + sorafenib vs sorafenib & TGFBR1 inhibitor & II & NCT02178358 & {$[157]$} \\
\hline
\end{tabular}


growth in xenograft tumors in mice [149]. Interestingly, it was proposed that $\mathrm{p} 53$ expression is upregulated by sorafenib in HCC cells, which would mediate some of its suppressor actions [150]. Other approaches deal with the MDM2-p53 binding, which could be inhibited in order to reactivate WT p53 in cancer cells [151], in fact the disruption of the binding between $\mathrm{p} 53$ and MDM2 can effectively induce apoptosis in HCC cells that overexpress MDM2 [152]. Furthermore, mimetics of p14ARF (a negative regulator of MDM2) inhibit MDM2-dependent degradation of p53 and, consequently, they activate its transcriptional activity [153]. Similarly, Nutlin-3, a MDM2 antagonist, induces apoptosis through downregulation of phospho-Ser392-p53 in HCC cells, which offers a new alternative to chemotherapy [154].

\section{- Targeting the TGF- $\beta$ pathway in HCC}

More complicated is regulating the TGF- $\beta$ pathway as a therapeutic strategy in HCC. As poorly differentiated HCC correlates with a late-TGF- $\beta$ signature, the use of specific inhibitors might be promising [51]. Indeed, blocking TGF- $\beta$ signaling in HCC cells, by using small molecules that inhibit receptor kinase activity, has proved to impair HCC cell migration and invasion, coincident with decreased expression of Smad 2 phosphorylation $[155,156]$. Consistently, silencing of the TGF- $\beta$ receptor- 1 , or its specific inhibition, partially recovers the epithelial phenotype of mesenchymal-like HCC cells [66]. Preliminary results from a Phase II clinical trial using the TGF- $\beta$ receptor- 1 inhibitor LY2157299 have shown improved clinical outcome and also changes consistent with a reduction of EMT [157] (Table 1). However, all these therapeutic approaches would need to take into consideration the tumor suppressor role that TGF- $\beta$ could be playing in some tumors. In this sense, a better knowledge of specific targets downstream TGF- $\beta$ that mediate its protumorigenic signals in HCC would facilitate the analysis of the TGF- $\beta$ signature in patients, to predict their response to a TGF- $\beta$-targeted therapy [66].

\section{Conclusion \& future perspective}

Research in cancer chemotherapy and targeted-therapies has proved that the ability to induce apoptosis in tumor cells is a major aspect to obtain a successful outcome. Most therapies inhibit tumor invasion and metastasis, hence stopping tumor progression, but fail to completely eliminate malignant cells. Regarding HCC, the design of effective therapies has been a challenge given that liver tumors are highly heterogeneous. Future will uncover a vast set of new molecular markers of HCC permitting a better classification of patient subpopulations and a more personalized therapeutic approach. In HCC therapy, patient stratification according to prognostic factors has shown an increased efficacy of targeted therapies avoiding the cover up of potential beneficial activities in certain patient cohorts [142]. Therefore, better knowledge of the drivers of liver tumorigenesis, both in terms of hepatocytes' alterations and of tumor microenvironment deregulation, will lead to more successful outcomes. Sorafenib has proven to increase its efficacy in inducing cell death in combination with other drugs, consequently, the use of combined therapies that will allow synergies is probably the most useful way to demolish the resistance to cell death in HCC. It is also important to point out that understanding the mechanisms by which treatment resistances are developed in HCC will lead to a future of effective combined therapies, as well as the establishment of secondary protocols of action.

During the last years, awareness has been raised on targeting anti-tumoral drugs specifically to tumor cells using nanoparticles as carriers that permit a better distribution and avoid secondary nondesired effects on nontumoral tissues $[158,159]$. This approach may benefit from molecular targets that are overexpressed on the surface of tumor cells. HCC patients are characterized by the high expression of several markers, such as EGFR, $\alpha 6 \beta 1$ integrin or CD44, hence the use of monoclonal antibodies or ligands/peptides in the case of receptors could be considered as promising therapeutical targets [159]. Indeed, migration assays performed using HCC cells demonstrate a higher inhibition efficiency of TGF- $\beta$ (using the TGF- $\beta$ receptor-1 kinase inhibitor LY2109761) in tailored biodegradable capsules compared with free LY2109761 administration [160]. In conclusion, although HCC treatments have not achieved the desired outcome so far, improved design, understanding and more integrative approaches will hopefully lead to better results in the future. 
Acknowledgements

Certain elements in the figures have been provided by Servier Medical Art (Servier).

Financial \& competing interests disclosure

Research in the authors' group is supported by grants from the Ministry of Economy and Competitiveness (MINECO), Spain (BFU2012-35538 and ISCIII-RTICC: RD12-0036-0029) and People Programme (Marie Curie Actions) of the European Union's Seventh Framework Programme (FP7/2007-2013) under REA grant agreement \# PITN-GA-2012-316549 (IT

\section{References}

Papers of special note have been highlighted as:

- of interest; $\bullet \bullet$ of considerable interest

1 Guicciardi ME, Gores GJ. Apoptosis: a mechanism of acute and chronic liver injury. Gut 54(7), 1024-1033 (2005).

2 Fabregat I, Roncero C, Fernandez M. Survival and apoptosis: a dysregulated balance in liver cancer. Liver Int. 27(2), 155-162 (2007).

3 Park YN, Chae KJ, Kim YB, Park C, Theise N. Apoptosis and proliferation in hepatocarcinogenesis related to cirrhosis. Cancer 92(11), 2733-2738 (2001).

4 Makino Y, Shiraki K, Sugimoto K et al. Histological features of cirrhosis with hepatitis $\mathrm{C}$ virus for prediction of hepatocellular carcinoma development: a prospective study. Anticancer Res. 20 (5C), 3709-3715 (2000).

5 Hytiroglou P, Park YN, Krinsky G, Theise ND. Hepatic precancerous lesions and small hepatocellular carcinoma. Gastroenterol. Clin. North Am. 36(4), 867-887, vii (2007).

6 Bruix J, Han KH, Gores G, Llovet JM, Mazzaferro V. Liver cancer: approaching a personalized care. J. Hepatol. 62(1S), S144-S156 (2015).

- Review on liver cancer therapeutics.

7 Deng GL, Zeng S, Shen H. Chemotherapy and target therapy for hepatocellular carcinoma: new advances and challenges. World J. Hepatol. 7(5), 787-798 (2015).

8 Schattenberg JM, Schuchmann M, Galle PR. Cell death and hepatocarcinogenesis: dysregulation of apoptosis signaling pathways. J. Gastroenterol. Hepatol. 26(Suppl. 1), 213-219 (2011).

9 Lee SH, Shin MS, Lee HS et al. Expression of Fas and Fas-related molecules in human hepatocellular carcinoma. Hum. Pathol. 32, 250-256 (2001).

10 Zou C, Chen J, Chen K et al. Functional analysis of miR-181a and Fas involved in hepatitis B virus-related hepatocellular

LIVER). The authors are also supported by the European Cooperation in Science and Technology (COST Action BM1203/EU-ROS). J Moreno-Càceres is recipient of a predoctoral contract from the Ministry of Education, Culture and Sport (MEC), Spain (\#AP2010-3036). The authors have no other relevant affliations or financial involvement with any organization or entity with a financial interest in or financial conflict with the subject matter or materials discussed in the manuscript apart from those disclosed.

No writing assistance was utilized in the production of this manuscript.

carcinoma pathogenesis. Exp. Cell. Res. 331(2), 352-361 (2015).

11 Ito $\mathrm{Y}$, Monden M, Takeda T et al. The status of Fas and Fas ligand expression can predict recurrence of hepatocellular carcinoma. $\mathrm{Br}$. J. Cancer 82(6), 1211-1217 (2000).

12 Shin EC, Shin JS, Park JH, Kim JJ, Kim H, Kim SJ. Expression of Fas-related genes in human hepatocellular carcinomas. Cancer Lett. 134, 155-162 (1998).

13 Takahashi M, Saito H, Okuyama T et al. Overexpression of $\mathrm{Bcl}-2$ protects human hepatoma cells from Fas-antibody-mediated apoptosis. J. Hepatol. 31, 315-322 (1999).

14 Lian Z, Liu J, Pan J et al. A cellular gene up-regulated by hepatitis B virus-encoded X antigen promotes hepatocellular growth and survival. Hepatology 34, 146-157 (2001).

15 Otsuka M, Kato N, Taniguchi H et al. Hepatitis $\mathrm{C}$ virus core protein inhibits apoptosis via enhanced $\mathrm{Bcl}-\mathrm{Xl}$ expression. Virology 296, 84-93 (2002).

16 Zhu H, Berkova Z, Mathur R et al. Hur suppresses Fas expression and correlates with patient outcome in liver cancer. Mol. Cancer Res. 13(5), 809-818 (2015).

17 Zhong W, Qin S, Zhu B et al. Oxysterolbinding protein-related protein 8 (ORP8) increases sensitivity of hepatocellular carcinoma cells to Fas-mediated apoptosis. J. Biol. Chem. 290(14), 8876-8887 (2015).

18 Okano H, Shiraki K, Inoue H et al. Cellular FLICE/caspase-8-inhibitory protein as a principal regulator of cell death and survival in human hepatocellular carcinoma. Lab. Invest. 83(7), 1033-1043 (2003).

19 Chan BC, Ching AK, To KF et al. BRE is an antiapoptotic protein in vivo and overexpressed in human hepatocellular carcinoma. Oncogene 27(9), 1208-1217 (2008).

20 Chui YL, Ching AK, Chen S et al. BRE over-expression promotes growth of hepatocellular carcinoma. Biochem. Biophys. Res. Commun. 391(3), 1522-1525 (2010).
21 Suzuki A, Hayashida M, Kawano H, Sugimoto K, Nakano T, Shiraki K. Hepatocyte growth factor promotes cell survival from fas-mediated cell death in hepatocellular carcinoma cells via Akt activation and Fas-death-inducing signaling complex suppression. Hepatology 32 (4 Pt 1), 796-802 (2000).

22 Suzuki H, Toyoda M, Horiguchi N et al. Hepatocyte growth factor protects against Fas-mediated liver apoptosis in transgenic mice. Liver Int. 29(10), 1562-1568 (2009).

23 Johnstone RW, Frew AJ, Smyth MJ. The trail apoptotic pathway in cancer onset, progression and therapy. Nat. Rev. Cancer 8(10), 782-798 (2008).

24 Chen XP, He SQ, Wang HP, Zhao YZ, Zhang WG. Expression of TNF-related apoptosis-inducing ligand receptors and antitumor tumor effects of TNF-related apoptosis-inducing ligand in human hepatocellular carcinoma. World J. Gastroenterol. 9(11), 2433-2440 (2003).

25 Herr I, Schemmer P, Buchler MW. On the trail to therapeutic intervention in liver disease. Hepatology 46(1), 266-274 (2007).

26 Du J, Liang X, Liu Y et al. Hepatitis B virus core protein inhibits TRAIL-induced apoptosis of hepatocytes by blocking DR5 expression. Cell Death. Differ. 16(2), 219-229 (2009).

27 Zender L, Hutker S, Mundt B et al. NFkappaB-mediated upregulation of Bcl-xl restrains TRAIL-mediated apoptosis in murine viral hepatitis. Hepatology 41(2), 280-288 (2005).

28 Liu N, Zuo C, Wang X et al. miR-942 decreases TRAIL-induced apoptosis through ISG12a downregulation and is regulated by AKT. Oncotarget 5(13), 4959-4971 (2014).

29 Massague J. TGFbeta in cancer. Cell 134(2), 215-230 (2008).

30 Carr BI, Hayashi I, Branum EL, Moses HL. Inhibition of DNA synthesis in rat hepatocytes by platelet-derived type beta 
transforming growth factor. Cancer Res. 46(5), 2330-2334 (1986).

31 Oberhammer FA, Pavelka M, Sharma S et al. Induction of apoptosis in cultured hepatocytes and in regressing liver by transforming growth factor beta 1. Proc. Natl Acad. Sci. USA 89(12), 5408-5412 (1992).

32 Sanchez A, Alvarez AM, Benito M, Fabregat I. Apoptosis induced by transforming growth factor-beta in fetal hepatocyte primary cultures: involvement of reactive oxygen intermediates. J. Biol. Chem. 271(13), 7416-7422 (1996).

33 Giannelli G, Rani B, Dituri F, Cao Y, Palasciano G. Moving towards personalised therapy in patients with hepatocellular carcinoma: the role of the microenvironment. Gut 63(10), 1668-1676 (2014).

34 Fabregat I, Sancho P. The transforming growth factor-beta (TGF-b) in liver fibrosis. In: TGF-Beta in Human Disease. Moustakas A, Keiji M (Eds). Springer, Japan, 255-277 (2013).

35 Matsuzaki K, Date M, Furukawa F et al. Autocrine stimulatory mechanism by transforming growth factor beta in human hepatocellular carcinoma. Cancer Res. 60 (5), 1394-1402 (2000).

36 Park SS, Eom YW, Kim EH et al. Involvement of c-SRC kinase in the regulation of TGF-beta1-induced apoptosis. Oncogene 23(37), 6272-6281 (2004).

37 Valdes F, Murillo MM, Valverde AM et al. Transforming growth factor-beta activates both pro-apoptotic and survival signals in fetal rat hepatocytes. Exp. Cell Res. 292(1), 209-218 (2004).

38 Murillo MM, del Castillo G, Sanchez A, Fernandez M, Fabregat I. Involvement of EGF receptor and c-SRC in the survival signals induced by TGF-betal in hepatocytes. Oncogene 24(28), 4580-4587 (2005).

39 Caja L, Ortiz C, Bertran E et al. Differential intracellular signalling induced by TGF-beta in rat adult hepatocytes and hepatoma cells: implications in liver carcinogenesis. Cell. Signal. 19(4), 683-694 (2007).

40 Sancho P, Bertran E, Caja L, CarmonaCuenca I, Murillo MM, Fabregat I. The inhibition of the epidermal growth factor (EGF) pathway enhances TGF-beta-induced apoptosis in rat hepatoma cells through inducing oxidative stress coincident with a change in the expression pattern of the NADPH oxidases (NOX) isoforms. Biochim. Biophys. Acta 1793(2), 253-263 (2009).

41 Caja L, Sancho P, Bertran E, Fabregat I. Dissecting the effect of targeting the epidermal growth factor receptor on TGF-beta-induced-apoptosis in human hepatocellular carcinoma cells. J. Hepatol. 55(2), 351-358 (2011).

42 Fabregat I, Herrera B, Fernandez M et al. Epidermal growth factor impairs the cytochrome C/Caspase-3 apoptotic pathway induced by transforming growth factor beta in rat fetal hepatocytes via a phosphoinositide 3-kinase-dependent pathway. Hepatology 32(3), 528-535 (2000).

43 Carmona-Cuenca I, Herrera B, Ventura JJ, Roncero C, Fernandez M, Fabregat I. EGF blocks nadph oxidase activation by TGF-beta in fetal rat hepatocytes, impairing oxidative stress, and cell death. J. Cell. Physiol. 207(2), 322-330 (2006).

44 Carmona-Cuenca I, Roncero C, Sancho P et al. Upregulation of the NADPH oxidase nox 4 by TGF-beta in hepatocytes is required for its pro-apoptotic activity. J. Hepatol. 49(6), 965-976 (2008).

45 Borrell-Pages M, Rojo F, Albanell J, Baselga J, Arribas J. Tace is required for the activation of the EGFR by TGF-alpha in tumors. Embo J. 22(5), 1114-1124 (2003).

46 Thiery JP. Epithelial-mesenchymal transitions in development and pathologies. Curr. Opin. Cell Biol. 15(6), 740-746 (2003).

47 Valdes F, Alvarez AM, Locascio A et al. The epithelial mesenchymal transition confers resistance to the apoptotic effects of transforming growth factor beta in fetal rat hepatocytes. Mol. Cancer Res. 1(1), 68-78 (2002).

48 Nitta T, Kim JS, Mohuczy D, Behrns KE. Murine cirrhosis induces hepatocyte epithelial mesenchymal transition and alterations in survival signaling pathways. Hepatology 48(3), 909-919 (2008).

49 Franco DL, Mainez J, Vega S et al. SNAIL1 suppresses TGF-beta-induced apoptosis and is sufficient to trigger EMT in hepatocytes. J. Cell. Sci. 123(Pt 20), 3467-3477 (2010).

50 Del Castillo G, Murillo MM, Alvarez-Barrientos A et al. Autocrine production of TGF-beta confers resistance to apoptosis after an epithelial-mesenchymal transition process in hepatocytes: role of EGF receptor ligands. Exp. Cell. Res. 312(15), 2860-2871 (2006).

51 Coulouarn C, Factor VM, Thorgeirsson SS. Transforming growth factor-beta gene expression signature in mouse hepatocytes predicts clinical outcome in human cancer. Hepatology 47(6), 2059-2067 (2008).

- Relevant in understanding the importance of TGF- $\beta$ signature status in HCC.
52 Yang YA, Zhang GM, Feigenbaum L, Zhang YE. Smad3 reduces susceptibility to hepatocarcinoma by sensitizing hepatocytes to apoptosis through downregulation of Bcl-2. Cancer Cell 9 (6), 445-457 (2006).

53 Dzieran J, Fabian J, Feng T et al. Comparative analysis of TGF-beta/Smad signaling dependent cytostasis in human hepatocellular carcinoma cell lines. PLoS ONE 8(8), e72252 (2013).

54 Liu N, Jiao T, Huang Y, Liu W, Li Z, Ye X. Hepatitis $\mathrm{B}$ virus regulates apoptosis and tumorigenesis through the microRNA-15aSmad7-transforming growth factor beta pathway. J. Virol. 89(5), 2739-2749 (2015).

55 Kitisin K, Ganesan N, Tang Y et al. Disruption of transforming growth factor-beta signaling through beta-spectrin elf leads to hepatocellular cancer through cyclin $\mathrm{d} 1$ activation. Oncogene 26(50), 7103-7110 (2007).

56 Baek HJ, Lim SC, Kitisin K et al. Hepatocellular cancer arises from loss of transforming growth factor beta signaling adaptor protein embryonic liver fodrin through abnormal angiogenesis. Hepatology 48(4), 1128-1137 (2008).

57 Mamiya T, Yamazaki K, Masugi Y et al. Reduced transforming growth factor-beta receptor II expression in hepatocellular carcinoma correlates with intrahepatic metastasis. Lab. Invest. 90 (9), 1339-1345 (2010).

58 Dooley S, Weng H, Mertens PR. Hypotheses on the role of transforming growth factor-beta in the onset and progression of hepatocellular carcinoma. Dig. Dis. 27(2), 93-101 (2009).

59 Ito N, Kawata S, Tamura $S$ et al. Elevated levels of transforming growth factor beta messenger RNA and its polypeptide in human hepatocellular carcinoma. Cancer Res. 51(15), 4080-4083 (1991).

60 Huang S, He X, Ding J et al. Upregulation of miR-23a approximately 27 a approximately 24 decreases transforming growth factor-betainduced tumor-suppressive activities in human hepatocellular carcinoma cells. Int. J. Cancer 123(4), 972-978 (2008).

61 Petrocca F, Vecchione A, Croce CM. Emerging role of miR-106b-25/miR-17-92 clusters in the control of transforming growth factor beta signaling. Cancer Res. 68(20), 8191-8194 (2008).

$62 \mathrm{Li} \mathrm{J}, \mathrm{Fu} \mathrm{H}, \mathrm{Xu} \mathrm{C}$ et al. miR-183 inhibits TGF-beta1-induced apoptosis by downregulation of PDCD4 expression in human hepatocellular carcinoma cells. $B M C$ Cancer 10, 354 (2010). 
63 Moreno-Caceres J, Caja L, Mainez J et al. Caveolin-1 is required for TGF-beta-induced transactivation of the EGF receptor pathway in hepatocytes through the activation of the metalloprotease TACE/ADAM17. Cell Death Dis. 5, e1326 (2014).

64 Meyer C, Dzieran J, Liu Y et al. Distinct dedifferentiation processes affect caveolin-1 expression in hepatocytes. Cell. Commun. Signal. 11(1), 6 (2013).

65 Tse EY, Ko FC, Tung EK et al. Caveolin-1 overexpression is associated with hepatocellular carcinoma tumourigenesis and metastasis. J. Pathol. 226(4), 645-653 (2012).

66 Bertran E, Crosas-Molist E, Sancho P et al. Overactivation of the TGF-beta pathway confers a mesenchymal-like phenotype and CXCR4-dependent migratory properties to liver tumor cells. Hepatology 58(6), 2032-2044 (2013).

67 Fransvea E, Angelotti U, Antonaci S, Giannelli G. Blocking transforming growth factor-beta up-regulates E-cadherin and reduces migration and invasion of hepatocellular carcinoma cells. Hepatology 47(5), 1557-1566 (2008).

68 Fischer AN, Fuchs E, Mikula M, Huber H, Beug H, Mikulits W. PDGF essentially links TGF-beta signaling to nuclear beta-catenin accumulation in hepatocellular carcinoma progression. Oncogene 26(23), 3395-3405 (2007).

69 van Zijl F, Mair M, Csiszar A et al. Hepatic tumor-stroma crosstalk guides epithelial to mesenchymal transition at the tumor edge. Oncogene 28(45), 4022-4033 (2009).

70 Mazzocca A, Fransvea E, Dituri F, Lupo L, Antonaci S, Giannelli G. Down-regulation of connective tissue growth factor by inhibition of transforming growth factor beta blocks the tumor-stroma cross-talk and tumor progression in hepatocellular carcinoma. Hepatology 51(2), 523-534 (2010).

71 Mott JL, Gores GJ. Piercing the armor of hepatobiliary cancer: $\mathrm{Bcl}-2$ homology domain 3 (BH3) mimetics and cell death. Hepatology 46(3), 906-911 (2007).

72 Takehara T, Liu X, Fujimoto J, Friedman SL, Takahashi H. Expression and role of Bcl-xl in human hepatocellular carcinomas. Hepatology 34(1), 55-61 (2001).

73 Sieghart W, Losert D, Strommer S et al. Mcl-1 overexpression in hepatocellular carcinoma: a potential target for antisense therapy. J. Hepatol. 44(1), 151-157 (2006).

74 Beerheide W, Tan YJ, Teng E, Ting AE, Jedpiyawongse A, Srivatanakul P.
Downregulation of proapoptotic proteins Bax and $\mathrm{Bcl}-\mathrm{X}(\mathrm{S})$ in $\mathrm{p} 53$ overexpressing hepatocellular carcinomas. Biochem. Biophys. Res. Commun. 273(1), 54-61 (2000).

Chen GG, Lai PB, Chan PK et al. Decreased expression of bid in human hepatocellular carcinoma is related to Hepatitis B virus $\mathrm{X}$ protein. Eur. J. Cancer 37(13), 1695-1702 (2001).

76 Shi YH, Ding WX, Zhou J et al. Expression of X-linked inhibitor-of-apoptosis protein in hepatocellular carcinoma promotes metastasis and tumor recurrence. Hepatology 48(2), 497-507 (2008).

77 Birkey Reffey S, Wurthner JU, Parks WT, Roberts AB, Duckett CS. X-linked inhibitor of apoptosis protein functions as a cofactor in transforming growth factor-beta signaling. J. Biol. Chem. 276(28), 26542-26549 (2001).

78 Wang K, Lin B. Inhibitor of apoptosis proteins (IAPS) as regulatory factors of hepatic apoptosis. Cell. Signal. 25(10), 1970-1980 (2013).

79 Augello C, Caruso L, Maggioni M et al. Inhibitors of apoptosis proteins (IAPS) expression and their prognostic significance in hepatocellular carcinoma. BMC Cancer 9, 125 (2009).

80 Lo SJ, Fan LC, Tsai YF et al. A novel interaction of nucleophosmin with $\mathrm{Bcl} 2$ associated $\mathrm{X}$ protein regulating death evasion and drug sensitivity in human hepatoma cells. Hepatology 57(5), 1893-1905 (2013).

81 Yang F, Li QJ, Gong ZB et al. Microrna-34a targets $\mathrm{Bcl}-2$ and sensitizes human hepatocellular carcinoma cells to sorafenib treatment. Technol. Cancer Res. Treat. 13(1), 77-86 (2014).

82 Fabregat I. Dysregulation of apoptosis in hepatocellular carcinoma cells. World J. Gastroenterol. 15(5), 513-520 (2009).

83 Muntane J, De la Rosa AJ, Docobo F, Garcia-Carbonero R, Padillo FJ. Targeting tyrosine kinase receptors in hepatocellular carcinoma. Curr. Cancer Drug Targets 13(3), 300-312 (2013).

84 Breuhahn K, Longerich T, Schirmacher P. Dysregulation of growth factor signaling in human hepatocellular carcinoma. Oncogene 25(27), 3787-3800 (2006).

85 Llovet JM, Bruix J. Molecular targeted therapies in hepatocellular carcinoma. Hepatology 48(4), 1312-1327 (2008).

86 Ortiz C, Caja L, Sancho P, Bertran E, Fabregat I. Inhibition of the EGF receptor blocks autocrine growth and increases the cytotoxic effects of doxorubicin in rat hepatoma cells: role of reactive oxygen species production and glutathione depletion. Biochem. Pharmacol. 75(10), 1935-1945 (2008).

87 De Toni EN, Kuntzen C, Gerbes AL et al. P60-c-SRC suppresses apoptosis through inhibition of caspase 8 activation in hepatoma cells, but not in primary hepatocytes. J. Hepatol. 46(4), 682-691 (2007).

88 Gao JJ, Inagaki Y, Xue X, Qu XJ, Tang W. C-Met: a potential therapeutic target for hepatocellular carcinoma. Drug Discov. Ther. 5(1), 2-11 (2011).

89 Trusolino L, Bertotti A, Comoglio PM. Met signalling: principles and functions in development, organ regeneration and cancer. Nat. Rev. Mol. Cell Biol. 11(12), 834-848 (2010).

90 Xie B, Tang C, Chen P, Gou YB, Xiao J, $\mathrm{Du} H$. The effect of hepatitis $B$ virus $X$ protein on the c-Met promoter activity in HepG2 cells. Zhonghua Gan Zang Bing Za Zhi 17(4), 292-296 (2009).

91 You H, Ding W, Dang H, Jiang Y, Rountree CB. C-Met represents a potential therapeutic target for personalized treatment in hepatocellular carcinoma. Hepatology 54(3), 879-889 (2011).

92 Jo M, Stolz DB, Esplen JE, Dorko K, Michalopoulos GK, Strom SC. Cross-talk between epidermal growth factor receptor and c-Met signal pathways in transformed cells. J. Biol. Chem. 275(12), 8806-8811 (2000).

93 Korhan P, Erdal E, Kandemis E et al. Reciprocal activating crosstalk between c-Met and caveolin 1 promotes invasive phenotype in hepatocellular carcinoma. PLoS ONE 9(8), e105278 (2014).

94 Yoshikawa H, Matsubara K, Qian GS et al. SOCS-1, a negative regulator of the JAK/STAT pathway, is silenced by methylation in human hepatocellular carcinoma and shows growth-suppression activity. Nat. Genet. 28(1), 29-35 (2001).

95 Niwa Y, Kanda H, Shikauchi Y et al. Methylation silencing of SOCS-3 promotes cell growth and migration by enhancing JAK/STAT and FAK signalings in human hepatocellular carcinoma. Oncogene 24(42), 6406-6417 (2005).

96 Ogata H, Kobayashi T, Chinen T et al. Deletion of the SOCS3 gene in liver parenchymal cells promotes hepatitis-induced hepatocarcinogenesis. Gastroenterology 131(1), 179-193 (2006).

97 Hong Y, Zhou L, Xie H, Wang W, Zheng S. Differences in antiproliferative effect of STAT3 inhibition in HCC cells with versus 
without HBV expression. Biochem. Biophys. Res. Commun. 461(3), 513-518 (2015).

98 Wei RC, Cao X, Gui JH et al. Augmenting the antitumor effect of trail by SOCS3 with double-regulated replicating oncolytic adenovirus in hepatocellular carcinoma. Hum. Gene Ther. 22(9), 1109-1119 (2011).

99 Xu G, Yang F, Ding CL et al. miR-221 accentuates IFNS anti-HCV effect by downregulating SOCS1 and SOCS3. Virology 462-463, 343-350 (2014).

100 Horie Y, Suzuki A, Kataoka E et al. Hepatocyte-specific Pten deficiency results in steatohepatitis and hepatocellular carcinomas. J. Clin. Invest. 113(12), 1774-1783 (2004).

101 Ruan ZP, Xu R, Lv Y et al. Pten enhances the sensitivity of human hepatocellular carcinoma cells to sorafenib. Oncol. Res. 20(2-3), 113-121 (2012).

102 He X, Zhu Z, Johnson C et al. PIK3IP1, a negative regulator of $\mathrm{PI} 3 \mathrm{~K}$, suppresses the development of hepatocellular carcinoma. Cancer Res. 68(14), 5591-5598 (2008).

103 Janku F, Kaseb AO, Tsimberidou AM, Wolff RA, Kurzrock R. Identification of novel therapeutic targets in the PI3K/AKT/mTOR pathway in hepatocellular carcinoma using targeted next generation sequencing. Oncotarget 5(10), 3012-3022 (2014).

104 Jiang J, Zhang Y, Guo Y et al. Microrna-3127 promotes cell proliferation and tumorigenicity in hepatocellular carcinoma by disrupting of PI3K/AKT negative regulation. Oncotarget 6(8), 6359-6372 (2015).

105 Min L, He B, Hui L. Mitogen-activated protein kinases in hepatocellular carcinoma development. Semin. Cancer Biol. 21(1), 10-20 (2011).

106 Calvisi DF, Ladu S, Gorden A et al. Ubiquitous activation of RAS and JAK/STAT pathways in human HCC. Gastroenterology 130(4), 1117-1128 (2006).

107 Delire B, Starkel P. The RAS/MAPK pathway and hepatocarcinoma: pathogenesis and therapeutic implications. Eur. J. Clin. Invest. 45(6), 609-623 (2015).

108 Caja L, Sancho P, Bertran E, Iglesias-Serret D, Gil J, Fabregat I. Overactivation of the MEK/ERK pathway in liver tumor cells confers resistance to TGF-\{beta\}-induced cell death through impairing up-regulation of the NADPH oxidase NOX4. Cancer Res. 69(19), 7595-7602 (2009).

109 Qiu GH, Xie H, Wheelhouse N et al. Differential expression of hDAB2IPA and $\mathrm{hDAB} 2 \mathrm{IPB}$ in normal tissues and promoter methylation of hDAB2IPA in hepatocellular carcinoma. J. Hepatol. 46(4), 655-663 (2007).
110 Di Gioia S, Bianchi P, Destro A et al. Quantitative evaluation of RASSF1A methylation in the non-lesional, regenerative and neoplastic liver. BMC Cancer 6, 89 (2006).

111 Hu L, Chen G, Yu H, Qiu X. Clinicopathological significance of RASSF1A reduced expression and hypermethylation in hepatocellular carcinoma. Hepatol. Int. 4(1), 423-432 (2010).

112 Schagdarsurengin U, Wilkens L, Steinemann $\mathrm{D}$ et al. Frequent epigenetic inactivation of the RASSF1A gene in hepatocellular carcinoma. Oncogene 22(12), 1866-1871 (2003).

113 Yoshida T, Hisamoto T, Akiba J et al. Spreds, inhibitors of the RAS/ERK signal transduction, are dysregulated in human hepatocellular carcinoma and linked to the malignant phenotype of tumors. Oncogene 25(45), 6056-6066 (2006).

114 Calvisi DF, Pinna F, Meloni F et al. Dual-specificity phosphatase 1 ubiquitination in extracellular signal-regulated kinasemediated control of growth in human hepatocellular carcinoma. Cancer Res. 68(11), 4192-4200 (2008).

115 Hussain SP, Schwank J, Staib F, Wang XW, Harris CC. Tp 53 mutations and hepatocellular carcinoma: insights into the etiology and pathogenesis of liver cancer. Oncogene 26(15), 2166-2176 (2007).

116 Marcel V, Catez F, Diaz JJ. P53, a translational regulator: contribution to its tumour-suppressor activity. Oncogene doi:10.1038/onc.2015.25 (2015) (Epub ahead of print).

117 Meng X, Franklin DA, Dong J, Zhang Y. MDM2-p53 pathway in hepatocellular carcinoma. Cancer Res. 74(24), 7161-7167 (2014).

118 Schulze K, Imbeaud S, Letouze E et al. Exome sequencing of hepatocellular carcinomas identifies new mutational signatures and potential therapeutic targets. Nat. Genet. 47(5), 505-511 (2015).

- Important advances in the identification of HCC drivers, which can be used as therapeutic targets.

119 Farazi PA, Glickman J, Horner J, Depinho RA. Cooperative interactions of $\mathrm{p} 53$ mutation, telomere dysfunction, and chronic liver damage in hepatocellular carcinoma progression. Cancer Res. 66(9), 4766-4773 (2006).

120 Wilhelm SM, Carter C, Tang L et al. Bay 43-9006 exhibits broad spectrum oral antitumor activity and targets the
RAF/MEK/ERK pathway and receptor tyrosine kinases involved in tumor progression and angiogenesis. Cancer Res. 64(19), 7099-7109 (2004).

121 Fernando J, Sancho P, Fernandez-Rodriguez CM et al. Sorafenib sensitizes hepatocellular carcinoma cells to physiological apoptotic stimuli. J. Cell. Physiol. 227(4), 1319-1325 (2012).

122 Fernando J, Malfettone A, Cepeda EB et al. A mesenchymal-like phenotype and expression of CD 44 predict lack of apoptotic response to sorafenib in liver tumor cells. Int. J. Cancer 136(4), e161-e172 (2015).

- Shows a mechanism by which HCCs can be resistant to sorafenib treatment.

123 Liu K, Liu S, Zhang W, Ji B, Wang Y, Liu Y. miR222 regulates sorafenib resistance and enhance tumorigenicity in hepatocellular carcinoma. Int. J. Oncol. 45(4), 1537-1546 (2014).

124 Lin YT, Lu HP, Chao CC. Oncogenic c-Myc and prothymosin-alpha protect hepatocellular carcinoma cells against sorafenib-induced apoptosis. Biochem. Pharmacol. 93(1), 110-124 (2015).

125 Giovannini C, Baglioni M, Baron Toaldo M et al. Notch3 inhibition enhances sorafenib cytotoxic efficacy by promoting GSK3b phosphorylation and p21 down-regulation in hepatocellular carcinoma. Oncotarget 4(10), 1618-1631 (2013).

126 Zhao D, Zhai B, He C et al. Upregulation of HIF-2alpha induced by sorafenib contributes to the resistance by activating the TGF-alpha/EGFR pathway in hepatocellular carcinoma cells. Cell. Signal. 26(5), 1030-1039 (2014).

127 Wang L, Jia D, Duan F et al. Combined anti-tumor effects of IFN-alpha and sorafenib on hepatocellular carcinoma in vitro and in vivo. Biochem. Biophys. Res. Commun. 422(4), 687-692 (2012).

128 Ishijima N, Kanki K, Shimizu H, Shiota G. Activation of AMP-activated protein kinase by retinoic acid sensitizes hepatocellular carcinoma cells to apoptosis induced by sorafenib. Cancer Sci. 106(5), 567-575 (2015).

129 Ganten TM, Koschny R, Haas TL et al. Proteasome inhibition sensitizes hepatocellular carcinoma cells, but not human hepatocytes, to trail. Hepatology 42(3), 588-597 (2005).

130 Pathil A, Armeanu S, Venturelli S et al. HDAC inhibitor treatment of hepatoma cells induces both trail-independent apoptosis and restoration of sensitivity to trail. Hepatology 43(3), 425-434 (2006). 
131 Hamed HA, Yamaguchi Y, Fisher PB, Grant S, Dent P. Sorafenib and HDAC inhibitors synergize with trail to kill tumor cells. J. Cell. Physiol. 228(10), 1996-2005 (2013).

132 Omar HA, Arafa el-SA, Maghrabi IA, Weng JR. Sensitization of hepatocellular carcinoma cells to Apo2l/TRAIL by a novel Akt/NF- $\mathrm{B}$ signalling inhibitor. Basic. Clin. Pharmacol. Toxicol. 114(6), 464-471 (2014).

133 Lee FA, Zee BC, Cheung FY et al. Randomized Phase II study of the X-linked inhibitor of apoptosis (XIAP) antisense AEG35156 in combination with sorafenib in patients with advanced hepatocellular carcinoma (HCC). Am. J. Clin. Oncol. (2014) (Epub ahead of print).

- Shows the possibility of combined therapy with sorafenib in order to increase apoptosis in liver tumors.

134 Liu W, Zhu F, Jiang Y, Sun D, Yang B, Yan H. SiRNA targeting survivin inhibits the growth and enhances the chemosensitivity of hepatocellular carcinoma cells. Oncol. Rep. 29(3), 1183-1188 (2013).

135 Shen J, Sun H, Meng Q et al. Simultaneous inhibition of tumor growth and angiogenesis for resistant hepatocellular carcinoma by co-delivery of sorafenib and survivin small hairpin RNA. Mol. Pharm. 11(10), 3342-3351 (2014).

136 Or YY, Chow AK, Ng L et al. Survivin depletion inhibits tumor growth and enhances chemosensitivity in hepatocellular carcinoma. Mol. Med. Rep. 10(4), 2025-2030 (2014).

137 Wang B, Ni Z, Dai X et al. The Bcl-2/xL inhibitor ABT-263 increases the stability of Mcl-1 mRNA and protein in hepatocellular carcinoma cells. Mol. Cancer 13, 98 (2014).

138 Ni Z, Wang B, Dai X et al. HCC cells with high levels of Bcl-2 are resistant to ABT-737 via activation of the ROS-JNK-autophagy pathway. Free Radic. Biol. Med. 70, 194-203 (2014).

139 Huether A, Hopfner M, Sutter AP, Baradari V, Schuppan D, Scherubl H. Signaling pathways involved in the inhibition of epidermal growth factor receptor by erlotinib in hepatocellular cancer. World J. Gastroenterol. 12(32), 5160-5167 (2006).

140 Zhu AX, Rosmorduc O, Evans TR et al. A Phase III, randomized, double-blind, placebo-controlled trial of sorafenib plus erlotinib in patients with advanced hepatocellular carcinoma. J. Clin. Oncol. 33(6), 559-566 (2015).

141 Tovar V, Alsinet C, Villanueva A et al. IGF activation in a molecular subclass of hepatocellular carcinoma and pre-clinical efficacy of IGF-1R blockage. J. Hepatol. 52(4), 550-559 (2010).

142 Worns MA, Galle PR. HCC therapies - lessons learned. Nat. Rev. Gastroenterol. Hepatol. 11(7), 447-452 (2014).

143 Munshi N, Jeay S, Li Y et al. ARQ 197, a novel and selective inhibitor of the human c-Met receptor tyrosine kinase with antitumor activity. Mol. Cancer. Ther. 9(6), 1544-1553 (2010).

144 Koh YW, Park YS, Kang HJ, Shim JH, Yu E. Met is a predictive factor for late recurrence but not for overall survival of early stage hepatocellular carcinoma. Tumour Biol. 36(7), 4993-5000 (2015).

145 Santoro A, Rimassa L, Borbath I et al. Tivantinib for second-line treatment of advanced hepatocellular carcinoma: a randomised, placebo-controlled Phase 2 study. Lancet Oncol. 14(1), 55-63 (2013).

- Shows a treatment option in cases of sorafenib resistance: c-Met inhibition as an alternative.

146 Jiang X, Feng K, Zhang Y et al. Sorafenib and DE605, a novel c-Met inhibitor, synergistically suppress hepatocellular carcinoma. Oncotarget 6(14), 12340-12356 (2015).

147 Lim HY, Heo J, Choi HJ et al. A Phase II study of the efficacy and safety of the combination therapy of the MEK inhibitor refametinib (bay 86-9766) plus sorafenib for asian patients with unresectable hepatocellular carcinoma. Clin. Cancer Res. 20(23), 5976-5985 (2014).

148 Bao JJ, Zhang WW, Kuo MT. Adenoviral delivery of recombinant DNA into transgenic mice bearing hepatocellular carcinomas. Hum. Gene Ther. 7(3), 355-365 (1996).

149 He X, Liu F, Yan J et al. Trans-splicing repair of mutant $\mathrm{p} 53$ suppresses the growth of hepatocellular carcinoma cells in vitro and in vivo. Sci. Rep. 5, 8705 (2015).

150 Wei JC, Meng FD, Qu K et al. Sorafenib inhibits proliferation and invasion of human hepatocellular carcinoma cells via up-regulation of $\mathrm{p} 53$ and suppressing foxm 1. Acta Pharmacol. Sin. 36(2), 241-251 (2015).

151 Brown CJ, Cheok CF, Verma CS, Lane DP. Reactivation of $\mathrm{p} 53$ : from peptides to small molecules. Trends Pharmacol. Sci. 32(1), 53-62 (2011).

152 Koom WS, Park SY, Kim W et al. Combination of radiotherapy and adenovirusmediated $p 53$ gene therapy for Mdm2overexpressing hepatocellular carcinoma. J. Radiat. Res. 53(2), 202-210 (2012).

153 Midgley CA, Desterro JM, Saville MK et al. An N-terminal p14ARF peptide blocks Mdm2-dependent ubiquitination in vitro and can activate $\mathrm{p} 53$ in vivo. Oncogene 19(19), 2312-2323 (2000).

154 Shi X, Liu J, Ren L et al. Nutlin-3 downregulates $\mathrm{p} 53$ phosphorylation on serine392 and induces apoptosis in hepatocellular carcinoma cells. BMB Rep. 47(4), 221-226 (2014).

155 Fransvea E, Mazzocca A, Antonaci S, Giannelli G. Targeting transforming growth factor (TGF)-betari inhibits activation of betal integrin and blocks vascular invasion in hepatocellular carcinoma. Hepatology 49(3), 839-850 (2009).

156 Dituri F, Mazzocca A, Peidro FJ et al. Differential inhibition of the TGF-beta signaling pathway in HCC cells using the small molecule inhibitor LY2157299 and the D10 monoclonal antibody against TGF-beta receptor type II. PLoS ONE 8(6), e67109 (2013).

157 Giannelli G, Villa E, Lahn M. Transforming growth factor-beta as a therapeutic target in hepatocellular carcinoma. Cancer Res. 74(7), 1890-1894 (2014).

158 Perez-Herrero E, Fernandez-Medarde A. Advanced targeted therapies in cancer: drug nanocarriers, the future of chemotherapy. Eur. J. Pharm. Biopharm. 93, 52-79 (2015).

159 Yan JJ, Liao JZ, Lin JS, He XX. Active radar guides missile to its target: receptor-based targeted treatment of hepatocellular carcinoma by nanoparticulate systems. Tumour Biol. 36(1), 55-67 (2015).

160 Baldassarre F, Vergaro V, Scarlino F et al. Polyelectrolyte capsules as carriers for growth factor inhibitor delivery to hepatocellular carcinoma. Macromol. Biosci. 12(5), 656-665 (2012). 